\author{
И.H. Hocc
}

\title{
ОСОБЕННОСТИ ДИАГНОСТИКИ ПОЗНАВАТЕЛЬНОЙ АКТИВНОСТИ КАК ФАКТОРА ПРОФЕССИОНАЛЬНОГО РАЗВИТИЯ ЛИЧНОСТИ
}

\begin{abstract}
Аннотация. В статье акцентируется внимание на проблеме познавательной активности персона, как факторе профессионального развития личности. Формулируется важная особенность профессиональной психодиагностики предметно-содержательного плана - взаимозависимость продуктивности профессиональной деятельности от интеллекта как динамической системы личности. Также исследуются особенности психологического измерения интеллектуальной активности человека, достигшего зрелого возраста, влияния расслоения интеллекта в период взросления человека, анализ инструментов диагностики, схем экспериментов, связи интеллектуальных особенностей с акцентуированными личностными чертами, периодами возрастных кризисов зрелости, особенности интеллектуальной активности в рамках региональной и профессиональной специфики.

В качестве основного методического подхода выбран лонгитюдный план исследования, проводившееся на протяжении девяти лет. Инструмент исследования многообразен. Он включал как качественные методы: наблюдение, экспертиза, опросы, интервью, так и тестовые процедуры.

Научная новизна исследования состоит в применении продольных и поперечных эмпирических “срезов» на обширной реальной выборке государственных служащих в прочессе их профессионализации и развитии. Результаты тестовых замеров сопоставлялись с конкретными объективными результатами профессиональной деятельности. Периодичность измерений и постоянная валидизация инструмента исследований дало возможность получить достоверные результаты во многом подтверждающие итоги зарубежных и отечественных диагностических программ. В качестве выводов следует подчеркнуть, что наиболее важной психологической характеристикой личностно-профессионального развития персонала является его познавательная активность, которая в практической психологии наиболее сложна и противоречива.
\end{abstract}

Ключевые слова: акцентуации личности, измерение интеллектуальной активности, продуктивность профессиональной деятельности, предметно-содержательный план, профессиональная диагностика, познавательная активность персонала, инструменты диагностики, возрастные кризисы зрелости, региональная специфика, профессиональная специфика.

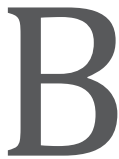

ажным фактором профессионального развития человека как индивида, личности и субъекта деятельности выступает его познавательная активность. Основываясь на многочисленных экспериментальных наблюдениях, Б.Г. Ананьев определил, что одно из центральных мест среди потенциалов человека занимает интеллект - «многоуровневая и многокомпонентная организация познавательных сил». «Нам представляется очень верной в методологическом отношении мысль, - отмечает А.А. Деркач, - высказанная Б.Г. Ананьевым о том, что в основе всякого развития лежит, прежде всего, развитие интеллек- туальное, т.е. развитие происходит при постоянном пополнении знаний, расширении кругозора, совершенствовании умений» ${ }^{1}$. «Интеллект, - отмечает А.А. Бодалев, - ... заземлен в жизнедеятельность, а его продуктивность зависит не только от степени овладения операциями и от характера мотивации, но, ..., и от энергетического обеспечения организмом процессов переработки информации и

Деркач А.А. Методолого-прикладные основы акмеологических исследований // Акмеология: личностное и профессиональное развитие человек. В 5-ти книгах. Кн. 1. М.: РАГС, 1999. C. 158. 


\section{Психология развития}

принятия решения, что выражается в так называемой «цене» интеллектуального напряжения»².

В связи с этим можно сформулировать важную особенность профессиональной психодиагностики предметно-содержательного плана - взаимозависимость продуктивности профессиональной деятельности от интеллекта как динамической системы личности. По нашим данным эффективно работающие подразделения, как правило, имеют более высокое среднее значение коэффициента интеллекта. Исключение составляют подразделения экспертно-аналитического профиля, в виду «пороговых значений коэффициента интеллекта» ${ }^{3}$.

Однако данная особенность носит комплексный характер и может расслаиваться по нескольким феноменам-тенденциям.

Первая тенденция может быть сформулирована следующим образом: интеллектуальная активность человека, достигшего зрелого возраста, представляется в виде ниспадающей кривой показателей. В качестве испытуемых в нашем исследовании принимали участие 374 человека. Распределение испытуемых по возрасту показано в таблице 1 и на рисунке 1.

Таблища 1

Распределение по возрасту испытуемых государственных органов

\begin{tabular}{|c|c|c|c|c|c|}
\hline $\begin{array}{c}\text { Возрастные } \\
\text { периоды }\end{array}$ & $\begin{array}{c}\mathbf{2 1 - 2 5} \\
\text { лет }\end{array}$ & $\begin{array}{c}\mathbf{2 6 - 3 0} \\
\text { лет }\end{array}$ & $\begin{array}{c}\mathbf{3 1 - 3 5} \\
\text { лет }\end{array}$ & $\begin{array}{c}\mathbf{3 6 - 4 0} \\
\text { лет }\end{array}$ & $\begin{array}{c}\mathbf{4 1 - 4 5} \\
\text { лет }\end{array}$ \\
\hline $\begin{array}{c}\text { Количество } \\
\text { испытуемых }\end{array}$ & 101 & 97 & 86 & 59 & 31 \\
\hline
\end{tabular}

Анализ экспериментальных данных когнитивных познавательных способностей персонала по результатам отработки интеллектуальных тестов Г. Айзенка, CFIT Р. Кеттелла, Дж. Равена, ТПА-САД 4 , корректурной пробы, проведенный методом «поперечных срезов» в 1998-2011 годах на материале организаций государственной службы, выявил

2 Бодалёв А.А. Вершина в развитии взрослого человека: характеристики и условия достижения. М.: Флинта: Наука, 1998. С. 157.

3 Анастази А., Урбина С. Психологическое тестирование. 7-е международное издание. СПб.: Питер, 2001. 688 с.; Дружинин В.Н. Психология общих способностей. СПб.: Питер, 2000. 368 с.; Крайг Г. Психология развития. 7-е международное издание. СПб.: Питер, 2002. 988 с.

4 Носс И.Н. О возможности использования методики семантического анализа деятельности (САД) в профориентационной диагностике мотивации призывной молодежи // Профессиональный психологический отбор в военно-учебном заведении. М.: ВПА, 1990. С. 36-39.

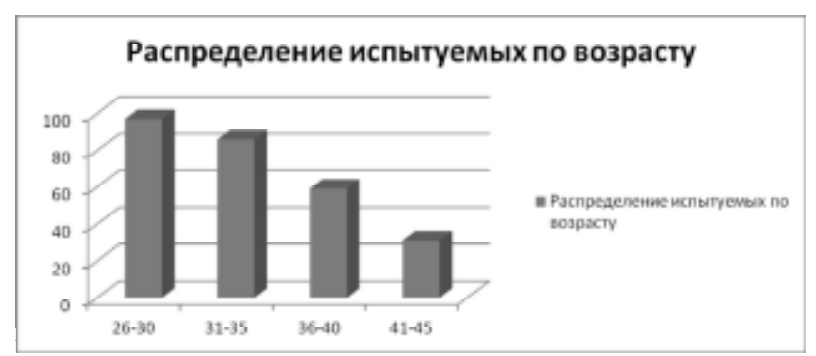

Рис. 1. Распределение испытуемых государственных органов по возрасту

статистически значимую отрицательную корреляцию показателей интеллекта с возрастными характеристиками сотрудников. Результаты представлены в таблицах 2 .

таблица 2

Корреляционная зависимость IQ от возраста испытуемых

\begin{tabular}{|c|c|c|c|c|c|}
\hline $\begin{array}{c}\text { Тесты } \\
\text { IQ }\end{array}$ & $\begin{array}{c}\text { IQ } \\
\text { по Aй- } \\
\text { зенку }\end{array}$ & CFIT & $\begin{array}{c}\text { Матрицы } \\
\text { Дж.К. } \\
\text { Равена }\end{array}$ & $\begin{array}{c}\text { TПА- } \\
\text { САД }\end{array}$ & $\begin{array}{c}\text { Корректур- } \\
\text { ная проба } \\
\text { (кольца) }\end{array}$ \\
\hline $\begin{array}{c}\text { Коэф- } \\
\text { фициент } \\
\text { корреляции }\end{array}$ & -0.94 & -0.91 & -0.73 & -0.86 & -0.95 \\
\hline
\end{tabular}

Эту тенденцию отражают и данные, помещенные в таблице 3, где значение так называемого коэффициента интеллекта у персонала подвержено общей тенденции к снижению в процессе усвоения профессионального алгоритма деятельности. Исключение составляют мыслительные функции, характеризующие комбинаторные, алгоритмические и вычислительные особенности, продуктивность которых со временем повышается. По мере приобретения опыта человеком активная интеллектуальная деятельность человека, основанная на восприятии и усвоении новой информации («текучий интеллект») «сворачивается» и трансформируется в готовые алгоритмы, при этом значимую роль начинают играть мотивация, система ценностей и личностные характеристики.

Таблица 3

Средние значения тестов IQ в соответствии с возрастом испытуемых

\begin{tabular}{|c|c|c|c|c|c|}
\hline $\begin{array}{c}\text { Возраст } \\
\text { (лет) }\end{array}$ & $\begin{array}{c}\text { Корректур- } \\
\text { ная проба } \\
\text { (кольца) }\end{array}$ & $\begin{array}{c}\text { IQ по } \\
\text { Айзен- } \\
\text { ку }\end{array}$ & CFIT & $\begin{array}{c}\text { Матрицы } \\
\text { Дж.К. } \\
\text { Равена }\end{array}$ & $\begin{array}{c}\text { ТПА- } \\
\text { САД }\end{array}$ \\
\hline $21-25$ & 68.8 & 106.0 & 29.7 & 22.05 & 18.3 \\
\hline $26-30$ & 68.1 & 105.0 & 28.8 & 21.3 & 17.64 \\
\hline $31-35$ & 68.9 & 102.0 & 26.2 & 19.46 & 17.12 \\
\hline $36-40$ & 66.6 & 102.0 & 24.8 & 18.6 & 14.11 \\
\hline $41-46$ & 67.0 & 97.6 & 27.3 & 16.26 & 15.46 \\
\hline
\end{tabular}


Полученные нами экспериментальные результаты согласуются с исследованиями «порогового интеллекта» Д. Перкинса ${ }^{5}$, У. Шнейдера, Г. Крайг, А. Анастази, В.Н. Дружинина и др. ${ }^{6}$. Исключение составляют данные, полученные на выборке людей, занимающихся информационно-технологической деятельностью. Здесь наблюдается падение познавательной активности сотрудников (независимо от пола) примерно до 40-летнего возраста, а затем её некоторый подъем. Экспериментальные факты дают возможность объяснить наблюдаемый эффект, по крайней мере, с четырех позиций. Первая точка зрения состоит в обоснованной констатации «расщепления» интеллекта, которое выражается в том, что в молодом возрасте (примерно до 30-40 лет) «пластичный»и «кристаллизованный» интеллекты слиты в единый ментальный фактор с приоритетной ролью познавательной активности («пластичного» интеллекта). С возрастом происходит расслоение («расщепление» данных слоев) и рост приоритетности «кристаллизованного» интеллекта, основанного на личностно-профессиональном опыте. Именно поэтому экспериментальные результаты обследования испытуемых зрелого возраста фиксируют рост комбинаторных мыслительных функций, общей умственной работоспособности и интеллектуальной продуктивности. Вторая позиция, объясняющая феномен снижения IQ в старших возрастных группах, заключается в анализе инструмента исследования. Так как измерение уровня и особенностей интеллекта происходит, как правило, с использованием тестов, разработанных под ситуацию обучения молодых людей ${ }^{7}$, то именно эту «обучаемость» они и измеряют (что сравнимо с оценкой «пластичного» интеллекта).

\footnotetext{
5 Холодная М.А. Психология интеллекта: парадоксы исследования. М.-Томск, СПЦ, 1997. 226 с.

6 См.: Дружинин В.Н. Психология общих способностей. 2-е изд. СПб.: Питер, 2000. С. 248-249; Крайг Г. Психология развития. 7-е медународное издание. СПб.: Питер, 2002. С. 770775; Анастази А., Урбина С. Психологическое тестирование. 7-е международное издание. СПб.: Питер, 2001. С. 361-368.

7 По оценкам зарубежных и отечественных авторов более $90 \%$ исследований по разработке и адаптации психологических методик и процедур осуществляется на т.н. «удобных» выборках, к которым относятся учащиеся колледжей и школ, студенты вузов, личный состав подразделений силовых ведомств и др. (См.: Девятко И.Ф. Диагностическая процедура в социологии. Очерк истории и теории. М.: Наука, 1993. 175 c. C. $12,24,26)$.
}

Комбинаторные, вычислительные, логические и иные ментальные функции, отражающие опыт человека не находят широкого исследования ввиду не разработанности соответствующих методик их диагностики. Эмпирические данные, полученные А. Смолом, показывают, что «сумма знаний с возрастом увеличивается и пожилые люди извлекают информацию из своей большей информационной базы (памяти) так же эффективно, как и более молодые из своей меньшей базы» ${ }^{8}$. Эта тенденция прослеживается и в наших исследованиях (табл. 4 и рис. 2).

Таблица 4

Данные лонгитюдных исследований познавательной активности персонала госучреждения (средние значения IQ)

\begin{tabular}{|c|c|c|c|c|c|c|}
\hline $\begin{array}{c}\text { Возрастные } \\
\text { диапазоны }\end{array}$ & $\begin{array}{c}\mathbf{2 0 - 2 5} \\
\text { лет }\end{array}$ & $\begin{array}{c}\mathbf{2 6 - 3 0} \\
\text { лет }\end{array}$ & $\begin{array}{c}\mathbf{3 1 - 3 5} \\
\text { лет }\end{array}$ & $\begin{array}{c}\mathbf{3 6 - 4 0} \\
\text { лет }\end{array}$ & $\begin{array}{c}\mathbf{4 1 - 4 5} \\
\text { лет }\end{array}$ & $\begin{array}{c}\mathbf{4 6 - 5 0} \\
\text { лет }\end{array}$ \\
\hline Показатели IQ & 108 & 107 & 104 & 104 & 103 & 94 \\
\hline
\end{tabular}

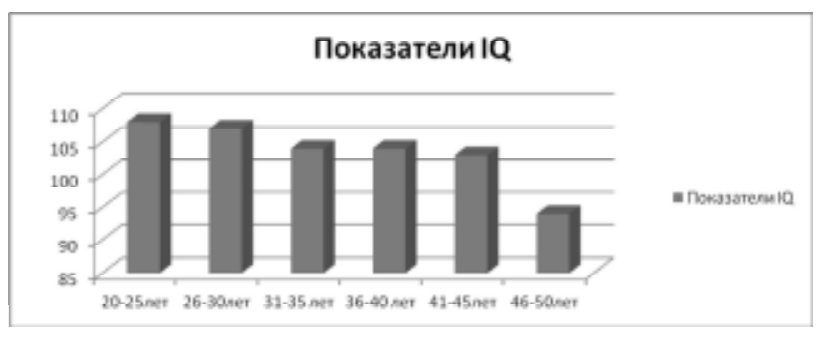

Рис. 2. Данные лонгитюдных исследований познавательной активности персонала госучреждения (средние значения IQ)

Третья позиция связана с предыдущими рассуждениями и состоит в том, что эксперименты изучения интеллектуальных особенностей строятся, как правило, по схемам «поперечных срезов». Поэтому показатели интеллекта представляются в номотетических рамках и статистические IQ отражают усредненные, абстрактные феномены. Г. Селье отмечал, что «абстракции бывают в такой же или даже в большей степени реальны, чем осязаемые конкретные факты» ${ }^{9}$. Эти абстракции и преподносятся научной общественности как конкретный факт. Что касается лонгитюдных исследований, выполненных по планам «продольных срезов», то, по

\footnotetext{
Смол А.М. Проектирование для пожилых людей // Человеческий фактор. В 6-ти тт. Т. 2 / Под ред. Г. Салвенди. М.: Мир, 1991. С. 468-469.

9 Селье Г. От мечты к открытию: Как стать учёным / Пер. с англ.; общ. ред. М.Н. Кондрашовой и И.С. Хорола. М.: Прогресс, 1987. С. 14.
} 
отзывам зарубежных исследователей ${ }^{10}$ до 40 летнего возраста наблюдается неуклонный его рост, а затем - плавный спад. В зависимости от уровня образования испытуемых интеллектуальный спад может не наступать вообще или даже обнаруживается прогрессивное повышение данных ${ }^{11}$.

Следует заметить, что возрастное снижение интеллектуальных способностей не является абсолютным психологическим фактом. Так «Сиэтлское лонгитюдное исследование (SLS) (1956-1991 г.г.) показало, что за первые шесть циклов исследований «возрастное снижение IQ весьма невелико или отсутствует вообще» ${ }^{12}$. Эту же тенденцию наблюдали К. Шайн и С. Стротер в исследованиях 1968 года пространственного мышления, числового счета, умозаключений и вербального мышления. Данные исследования послужили основанием для разработки теста Шайна-Терстоуна, который применяется в психодиагностике с 80-х годов для исследования интеллекта взрослых людей ${ }^{13}$.

По нашим данным за пять лет исследований показатели экспериментальной группы испытуемых изменялись в ту или иную сторону не значимо $^{14}$ (табл. 5, рис. 3).

Таблица 5

Результаты лонгитюдного исследования

\begin{tabular}{|c|c|c|c|c|c|}
\hline $\begin{array}{c}\text { Период } \\
\text { тестирования }\end{array}$ & 1 год & 2 года & 3 года & 4 года & 5 лет \\
\hline $\begin{array}{c}\text { Показатели IQ сотруд- } \\
\text { ников 25-30 летнего } \\
\text { возраста в ходе 5-лет- } \\
\text { него исследования }\end{array}$ & 115 & 105 & 104 & 108 & 106 \\
\hline
\end{tabular}

Четвертая точка зрения на факт снижения интеллектуальной составляющей способностей зрелого человека заключается в интерпретации этого феномена как следствия ухудшения общего состояния здоровья и таких особенностей поведения

10 Анастази А., Урбина С. Психологическое тестирование. 7-е международное издание. СПб.: Питер, 2001. С. 363.

11 Крайг Г. Психология развития. 7-е международное издание. СПб.: Питер, 2002. С.773.

12 Бурлачук Л.Ф. Психодиагностика. Учебник для возов. СПб: Питер, 2005. С. 225.

13 Анастази А., Урбина С. Психологическое тестирование. 7-е международное издание. СПб.: Питер, 2001. С. 365.

14 Показатель первичного измерения отражает ситуацию тестирования в ходе отбора при трудоустройстве, подтверждая тенденцию активного влияния на показатели интеллекта мотивации конкурсного поведения.

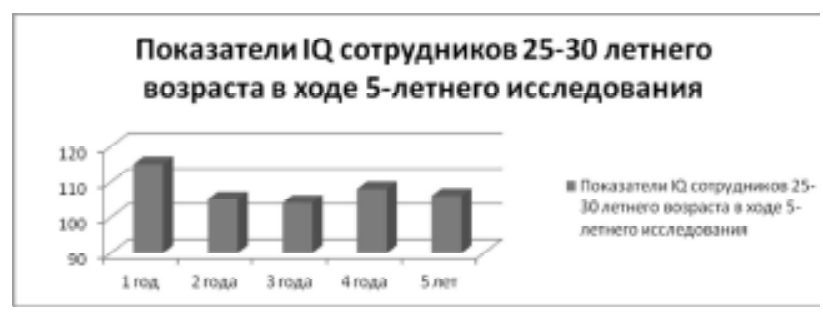

Рис. 3. Результаты лонгитюдного исследования

как развивающихся с возрастом медлительности, избирательности обучения, вкусов и предпочтений, осторожности, проявляемой при обследованиях, стремлении к безопасности и др. ${ }^{15}$.

Вторая тенденция обнаруживается в понижении интеллектуальной активности связанной $c$ наличием у человека акцентуированных личностных черт. В рамках клинической психологии некоторые исследователи интеллекта связывают его динамику с определенным видом патологических изменений характера испытуемых ${ }^{16}$. По нашим данным имеют место факты понижения интеллектуальных характеристик у лиц с акцентуациями характера из числа сотрудников, занимающихся информационно-коммуникативной деятельностью. Однако следует учитывать так называемую «профильную акцентуацию характера ${ }^{17}$, которая ждет своего кропотливого исследователя.

Системообразующая роль интеллекта подчеркивается во многих работах ${ }^{18}$. По нашим данным познавательная активность работников связана с основными характерологическими и поведенческими особенностями. В таблице 6 приведены некоторые корреляции с личностными методиками $^{19}$, подтверждающие предыдущие утверждения.

15 Смол А.М. Проектирование для пожилых людей // Человеческий фактор. В 6-ти тт. Т. 2 / Под ред. Г. Салвенди. М.: Мир, 1991. С. 471.

16 Собчик Л.Н. СМИЛ. Стандартизированный многофакторный метод исследования личности. СПб.: Речь, 2003. 216 с.

17 Выраженные черты личности, способствующие эффективности работы и являющимися профессиональноважными.

18 Анастази А., Урбина С. Психологическое тестирование. 7-е международное издание. СПб.: Питер, 2001. 688 с.; Бодалёв А.А. Вершина в развитии взрослого человека: характеристики и условия достижения. М.: Флинта: Наука, 1998. 168 с.; Дружинин В.Н. Психология общих способностей. СПб.: Питер, 2000. 368 с.

19 СМИЛ (2-я, 4-я, 6-я, 7-я, 8-я, 9-я, 0-я шкалы), pf-тест Дж.Розенцвейга (i, OD), ТЦВ М. Люшера (OAH, тревожность). 
Соотношение характерологических и поведенческих переменных и познавательной активности сотрудников $\left(\mathbf{R}_{\mathrm{xy}}\right)$.

\begin{tabular}{|c|c|c|c|c|c|c|c|c|c|c|c|}
\hline 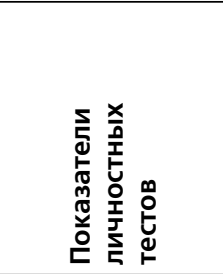 & 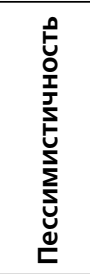 & 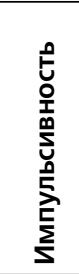 & 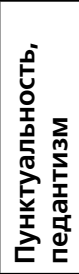 & 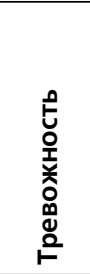 & 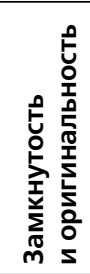 & 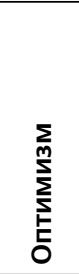 & 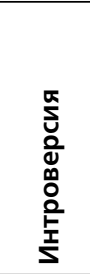 & 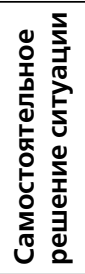 & 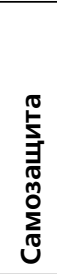 & 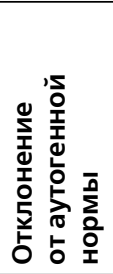 & 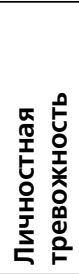 \\
\hline $\mathrm{IQ}$ & -0.96 & & 0.9 & -0.89 & 0.72 & 0.89 & -0.99 & -0.9 & 0.9 & 0.87 & \\
\hline $\begin{array}{l}\text { Познавательные } \\
\text { функции }\end{array}$ & & -0.8 & & & -0.76 & & & & & & -0.7 \\
\hline
\end{tabular}

Третья тенденция отражает неустойчивость показателей интеллектуальной активности в периоды возрастных кризисов зрелости. Б.Г. Ананьев, Я.А. Пономарев, Д.И. Фельдштейн, Д.Б. Эльконин, Г. Крайг, В.И. Слободчиков, Е.И. Исаев, Э. Эриксон и др., писали о так называемых кризисах личностно-профессионального развития, когда происходят сначала скрытые, а затем явные существенные преобразования картины мира, которая имелась у человека, в его ценностных ориентациях и их иерархии, в стратегии и тактике решения жизненных задач различной сложности и т.д. Этот эффект подтвердился и в процессе наших исследований, в ходе которых выявлено, что возрастные кризисы находят своё выражение в динамике и неустойчивости общей картины интеллектуальных характеристик сотрудников именно в эти возрастные моменты их жизни.

Четвертая тенденция проявляется в особенностях интеллектуальной активности относительно региональной и профессиональной специфики. «Можно утверждать вполне определенно, - отмечает A.A. Бодалев, - что общности людей, объединенных по профессиональному признаку, в зависимости от своей социальной зрелости, компетентности в своей сфере, сложившихся в них социально-психологических особенностей, влияя на общие жизненные позиции каждого своего члена как личности, вместе с тем весьма жестко «прорисовывают» «перспективную линию» движения его как субъекта деятельности в избранной им области профессионального труда» ${ }^{20}$. По нашим данным, существует значимая связь познаватель-

20 Бодалёв А.А. Вершина в развитии взрослого человека: характеристики и условия достижения. М.: Флинта: Наука, 1998. C. 65. ной активности сотрудников именно с функциональной стороной их профессиональной деятельности. Также выявлено статистически значимые различия познавательных способностей сотрудников основных специальностей исследуемой выборки в различных регионах России. То есть, интеллектуальные и в целом личностно-профессиональные характеристики персонала имеют выраженную как профессиональную, так и региональную спецификацию. Так, например, наиболее высокий уровень интеллекта отмечается у представителей информационно-аналитических отделов, занимающихся экспертизой экономической документации и аудиторской деятельностью. Наименьший уровень познавательной активности характерен для специалистов, обеспечивающих охрану объектов и проверку документов посетителей и сотрудников. Региональная спецификация личностно-профессионального развития может проявляться и в сфере интеллектуальной активности человека ${ }^{21}$ (табл. 7).

В качестве вывода следует подчеркнуть, что наиболее важной психологической характеристикой личностно-профессионального развития персонала является его познавательная активность, которая в практической психологии наиболее сложна и противоречива. Можно встретить различные суждения относительно роли этой категории в структуре личности и сознания человека, но неоспоримой является понимание интеллекта как системообразующего элемента в поведении и деятельности индивида. Различные спекуляции в психологии от придания дискриминативной зна-

21 Линн Р. Расовые различия в интеллекте. Эволюционный анализ / Пер. с англ. Д.О. Румянцев. М.: Профит Стайл, 2010. $304 \mathrm{c}$. 
Значение уровня интеллекта (IQ) по специальностям и регионам

\begin{tabular}{|c|c|c|c|c|c|}
\hline IQ по Г. Айзенку* & $\begin{array}{c}\text { Информационно- } \\
\text { коммуникационные } \\
\text { специальности }\end{array}$ & $\begin{array}{c}\text { Информационно- } \\
\text { поисковые } \\
\text { специальности }\end{array}$ & $\begin{array}{c}\text { Специальности } \\
\text { служб безопас- } \\
\text { ности }\end{array}$ & $\begin{array}{c}\text { Контрольно- } \\
\text { постовые } \\
\text { специальности }\end{array}$ & $\begin{array}{c}\text { Информационно- } \\
\text { аналитические } \\
\text { специальности }\end{array}$ \\
\hline Москва & 11,5 & 12,1 & 12,3 & 7.0 & 11,7 \\
\hline Санкт-Петербург & 10,1 & 12,2 & 12,4 & 12,6 & 11,8 \\
\hline Тульская обл. & 18,5 & 19.0 & 16,7 & 13,9 & 20,5 \\
\hline Башкортостан & 18,3 & нет данных & 11,2 & 10,4 & 23,1 \\
\hline Оренбургская обл. & 15,95 & 11,5 & 12,2 & 10,9 & 12,8 \\
\hline Свердловская обл. & 13,55 & нет данных & 10,8 & 11,2 & 13,8 \\
\hline Средние значения & 14,7 & 13,7 & 12,6 & 11,8 & 15,6 \\
\hline
\end{tabular}

* «Сырые» значения показателей по тесту интеллекта Г. Айзенка.

чимости так называемого «уровня интеллекта» до закрепления за ним статуса абстракции приводят к одному методологически неверному результату - выхолащиванию содержания данной категории, размывания ее границ, устранения ее из моделей практического исследования и низведения инструментов оценки интеллекта к роли обычных игрушек-головоломок, способствующих пустому времяпрепровождению. Нам представляется, что приведенный в данной статье некоторый анализ сформирует позитивное отношение основной массы практических психологов и приведет их кеще большей активности в изучении и главное в применении инструментальных методов изучения интеллектуальной сферы личностно-профессионального развития людей труда.

\section{Список литературы:}

1. Анастази А., Урбина С. Психологическое тестирование. 7-е международное издание. СПб.: Питер, 2001. $688 \mathrm{c}$.

2. Бодалёв А.А. Вершина в развитии взрослого человека: характеристики и условия достижения. М.: Флинта: Наука, 1998. 168 с.

3. Бурлачук Л.Ф. Психодиагностика. Учебник для возов. СПб.: Питер, 2005. 351 с.

4. Девятко И.Ф. Диагностическая процедура в социологии. Очерк истории и теории. М.: Наука, 1993.175 с.

5. Деркач А.А. Методолого-прикладные основы акмеологических исследований // Акмеология: личностное и профессиональное развитие человек. В 5-ти книгах. Кн. 1. М.: РАГС, 1999. 392 с.

6. Дружинин В.Н. Психология общих способностей. СПб.: Питер, 2000. 368 с.

7. Крайг Г. Психология развития. 7-е международное издание. СПб.: Питер, 2002.988 с.

8. Линн Р. Расовые различия в интеллекте. Эволюционный анализ / Пер. с англ. Д.О. Румянцев. М.: Профит Стайл, 2010. 304 с.

9. Носс И.Н. О возможности использования методики семантического анализа деятельности (САД) в профориентационной диагностике мотивации призывной молодежи // Профессиональный психологический отбор в военно-учебном заведении. М.: ВПА, 1990. С. 36-39.

10. Селье Г. От мечты к открытию: Как стать учёным / Пер. с англ.; общ. ред. М.Н. Кондрашовой и И.С. Хорола. М.: Прогресс, 1987. 368 с.

11. Слободчиков В.И., Исаев Е.И. Основы психологической антропологии. Психология развития человека: Развитие субъективной реальности в онтогенезе: Учебное пособие для вузов. М.: Школьная пресса, 2000. $416 \mathrm{c}$.

12. Смол А.М. Проектирование для пожилых людей // Человеческий фактор. В 6-ти тт. Т. 2 / Под ред. Г. Салвенди. М.: Мир, 1991. С. 457-474.

13. Собчик Л.Н. СМИЛ. Стандартизированный многофакторный метод исследования личности. СПб.: Речь, 2003. 216 с.

14. Холодная М.А. Психология интеллекта: парадоксы исследования. М.-Томск, СПЦ, 1997. 226 с. 


\section{Психология и психотехника 5(68) • 2014}

\section{References (transliteration):}

1. Anastazi A., Urbina S. Psikhologicheskoe testirovanie. 7-e mezhdunarodnoe izdanie. SPb.: Piter, 2001. 688 s.

2. Bodalev A.A. Vershina v razvitii vzroslogo cheloveka: kharakteristi-ki i usloviya dostizheniya. M.: Flinta: Nauka, 1998. $168 \mathrm{~s}$.

3. Burlachuk L.F. Psikhodiagnostika. Uchebnik dlya vozov. SPb.: Piter, 2005. $351 \mathrm{s.}$

4. Devyatko I.F. Diagnosticheskaya protsedura v sotsiologii. Ocherk istorii i teorii. M.: Nauka, 1993.175 s.

5. Derkach A.A. Metodologo-prikladnye osnovy akmeologicheskikh issledovanii // Akmeologiya: lichnostnoe i professional'noe razvitie chelovek. V 5-ti knigakh. Kn. 1. M.: RAGS, 1999. 392 s.

6. Druzhinin V.N. Psikhologiya obshchikh sposobnostei. SPb.: Piter, 2000. 368 s.

7. Kraig G. Psikhologiya razvitiya. 7-e mezhdunarodnoe izdanie. SPb.: Piter, 2002. $988 \mathrm{s.}$

8. Linn R. Rasovye razlichiya v intellekte. Evolyutsionnyi analiz / Per. s angl. D.O. Rumyantsev. M.: Profit Stail, 2010. $304 \mathrm{~s}$.

9. Noss I.N. O vozmozhnosti ispol'zovaniya metodiki semanticheskogo analiza deyatel'nosti (SAD) v proforientatsionnoi diagnostike motivatsii prizyvnoi molodezhi // Professional'nyi psikhologicheskii otbor $\mathrm{v}$ voenno-uchebnom zavedenii. M.: VPA, 1990. S. 36-39.

10. Sel'e G. Ot mechty k otkrytiyu: Kak stat' uchenym / Per. s angl.; obshch. red. M.N. Kondrashovoi i I.S. Khorola. M.: Progress, 1987. 368 s.

11. Slobodchikov V.I., Isaev E.I. Osnovy psikhologicheskoi antropologii. Psikhologiya razvitiya cheloveka: Razvitie sub"ektivnoi real'nosti v ontogeneze: Uchebnoe posobie dlya vuzov. M.: Shkol'naya pressa, 2000. $416 \mathrm{~s}$.

12. Smol A.M. Proektirovanie dlya pozhilykh lyudei // Chelovecheskii faktor. V 6-ti tt. T. 2 / Pod red. G. Salvendi. M.: Mir, 1991. S. 457-474.

13. Sobchik L.N. SMIL. Standartizirovannyi mnogofaktornyi metod issledovaniya lichnosti. SPb.: Rech', 2003. $216 \mathrm{~s}$.

14. Kholodnaya M.A. Psikhologiya intellekta: paradoksy issledovaniya. M.-Tomsk, SPTs, 1997. 226 s. 